\title{
A TEORIA DA ICONICIDADE VERBAL, DE DARCILIA SIMÕES, APLICADA À INTERPRETAÇÃO DO SIGNO INSÓLITO
}

Eleone Ferraz de Assis

Resumo: Este estudo dedicou-se a descrever e interpretar a tessitura textual dos fenômenos insólitos no romance Sombras de Reis Barbudos, de José J. Veiga, com base na associação entre a Teoria da Iconicidade Verbal e o insólito ficcional. Centrou-se, especificamente, nas marcas linguísticas que representam ideias ou conduzem o intérprete à percepção de que o insólito é construído no texto por meio de itens léxicos que constituem pistas icônicas. Merecem especial interesse, sobretudo, os substantivos, que, por serem palavras com alta iconicidade, participam da construção/representação de fenômenos insólitos e criam, por meio da trilha léxica, o itinerário de leitura para o texto-córpus. Fundamentou-se a discussão no insólito como categoria essencial do fantástico modal (BESSIÈRE, 2009; COVIZZI, 1978; FURTADO, s.d.; PRADA OROPREZA, 2006) e na Semiótica de extração peirceana, com enfoque na Teoria da Iconicidade Verbal (SIMÕES, 2007-2009). A análise comprova que os substantivos, como categorias linguísticas caracterizáveis semanticamente, têm a função designatória ou de nomeação na arquitetura de um texto em que se manifesta o insólito. Revela também que a incongruência lexical constitui-se em uma chave para a construção do ilógico, mágico, fantástico, misterioso, sobrenatural, irreal e suprarreal no texto-córpus.

Palavras-chave: Insólito. Iconicidade Verbal. Sombras de Reis Barbudos.

Abstract: The objective herein is to describe and understand the textual tessiture of the insolite phenomena in the novel Sombras de Reis Barbudos, by José J. Veiga, based on the association between the Theory of Verbal Iconicity and fictional insolite. It focused specifically in the linguistic marks that represent ideas or lead the interpreter to the perception of how the insolite is constructed in the text, by means of lexical items that constitute iconic hints. In the study, nouns are given a special attention, above all the other word categories, because, being words with a high inconicity level, they take part in the construction/ representation of the insolite phenomena and create, by means of the 
lexical path, the reading itinerary to the text-corpus. This study justified discussion on the insolite as an essential category of the Fantastic as a mode (BESSIÈRE, 2009; COVIZZI, 1978; FURTADO, s.d.; PRADA OROPREZA, 2006) and on the Peircean Semiotic, which highlights the Verbal Iconicity Theory (SIMÕES, 2007, 2009) The analysis proves that nouns, as a linguistic class that can be semantically categorized, have either designation or nominative functions in the construction of a text in which the insolite is manifested. It also reveals that the lexical incongruence constitutes itself a key to the construction of the illogical, magical, fantastic, mysterious, supernatural, unreal and super real in the corpus text.

Keywords: The Insolite. Verbal Iconicity. Sombras de Reis Barbudos.

\section{CONSIDERAÇÕES INICIAIS}

Este trabalho é um recorte de minha tese de doutoramento, intitulada "Escolhas lexicais e iconicidade textual: uma análise do insólito no romance Sombras de Reis Barbudos". Essa tese foi orientada pela brilhante pesquisadora, professora doutora Darcilia Simões, e defendida, em 2014, no Programa de Pós-Graduação em Letras, especialidade Língua Portuguesa. A pesquisa, além de ser orientada por essa professora, fundamenta-se na Teoria da Iconicidade Verbal que ela edificou.

O objetivo deste artigo é descrever e analisar a incongruência lexical dos fenômenos insólitos no romance Sombras de Reis Barbudos, de José J. Veiga, com base na Teoria da Iconicidade Verbal. Centra-se, especificamente, nas marcas linguísticas que representam ideias ou conduzem 
o intérprete à percepção de que o insólito é construído no texto por meio de itens léxicos que constituem pistas icônicas. Merecem especial interesse, sobretudo, os substantivos (muros, urubus e homens-passáros), que, por serem palavras com alta iconicidade, participam da construção/representação de fenômenos insólitos e criam, por meio da trilha léxica, o itinerário de leitura para o texto-córpus ${ }^{1}$.

Este estudo fundamenta-se na Teoria da Iconicidade Verbal (SIMÕES, 2009) e no insólito ficcional (ARÁN, 1999; CASAS, 2010). Em face disso, busca-se analisar o modo como é selecionado o léxico, o qual permite a criação de uma rede semiótica especial capaz de acionar esquemas cognitivos que levam à compreensão e à interpretação do romance. Essa rede semiótica é gerada pela incongruência lexical e produz uma iconicidade ativadora de imagens que facilitam o entendimento da obra.

Dado o propósito de examinar como o léxico se articula na constituição do insólito, a opção por limitar o córpus desta pesquisa a Sombras de Reis Barbudos deve-se às características singulares desse romance. Ele é constituído por signos que representam iconicamente o insólito no plano lexical.

1 Emprega-se a forma aportuguesada, segundo o paradigma das paroxítonas terminadas em -us, tal como bônus, tônus, etc. 
Para tanto, este estudo, em primeiro lugar, discorre sobre a Teoria da Iconicidade Verbal, de Darcilia Simões. Em seguida, discute a interpretação dos signos insólitos e seus limites. Finalmente, apresenta a análise da iconicidade lexical em passagens insólitas do romance Sombras de Reis Barbudos, de José J. Veiga.

\section{A TEORIA DA ICONICIDADE VERBAL}

A Teoria da Iconicidade Verbal - TIV - parte da Semiótica de extração peirceana e, nesta pesquisa, é eleita como o caminho para a análise da iconicidade lexical dos fenômenos insólitos. Essa teoria começou a ser edificada pela professora Darcilia Simões, da Universidade do Estado do Rio de Janeiro (UERJ), em sua tese de doutoramento, intitulada "O livrosem-legenda e a redação", defendida no programa de PósGraduação em Letras Vernáculas da Universidade Federal do Rio de Janeiro (SIMÕES, 1994).

Simões (2009, p. 68) delineou a TIV com o intuito "de criar-se uma base teórica, que observasse o signo ${ }^{2}$ em sua materialidade (sonora ou visual)" de modo a desenvolver uma proposta metodológica para o ensino de língua materna na perspectiva imagética e diagramática; ou seja, sua proposta visa aperfeiçoar os processos de leitura e produção textual

2 Nesta pesquisa, utiliza-se o conceito de signo como algo que denota um objeto perceptível ou simplesmente imaginável (SANTAELLA, 2000; SIMÕES, 2009). 
por meio da iconicidade desencadeada pela estrutura léxica do texto. Em outras palavras, essa teoria permite investigar minuciosamente a estrutura sígnica de um texto em busca do sentido construído na trama textual. Isso só é possível porque a perspectiva de análise parte da interação entre o texto e o intérprete.

Assim, essa teoria se fundamenta na relação entre o signo e o objeto (ícone, índice e símbolo) e tem "como objetivo maior subsidiar o entendimento da semiose textual e das consequências semióticas derivadas da interação entre sujeito e texto sob as interferências do contexto de produção da interlocução" (SIMÕES, 2009, p. 60). Desse modo, a estudiosa concebe que os sentidos de um texto são construídos no tecido social.

Buscando esclarecer, nesta pesquisa, o que se entende pela relação do signo com seu objeto, o ícone é definido como um signo que se assemelha ao seu objeto porque sua qualidade ou caraterística pertence ao próprio signo de modo a confirmar essa semelhança (SANTAELLA, 2000). Isto é, o ícone, além de representar formas e sentimentos, tem um alto poder de sugestão por ter agregado a si hipotéticas relações de similaridade. O índice é um signo que, por uma conexão dinâmica com o objeto, estabelece uma relação de causalidade, 
temporalidade e espacialidade. Enquanto o símbolo é um signo cuja relação com o objeto é arbitrária por depender das convenções sociais, sua virtude "está na generalidade da lei, regra, hábito ou convenção de que ele é portador e a [sua] função como signo dependerá precisamente dessa lei ou regra que determinará seu interpretante" (SANTAELLA, 2000, p. 132).

Simões (2009, p. 59) defende, na TIV, que, por seu caráter icônico, as unidades léxicas fazem emergir na mente do intérprete "valores de natureza semiótica e semântica". Esta estuda as significações concretizadas em um sistema linguístico em uso; aquela explora o "processo de produção de sentido a partir da análise das funções-valores que os signos eleitos pelo produtor do texto adquirem na trama textual" (SIMÕES, 2009, p. 59). Há, portanto, uma relação estreita entre o léxico utilizado na tessitura textual e os processos de semioses geradas pelo texto.

A função lexicológico-semiótica faz das palavras (signos atualizados em contextos frasais) signos evocadores de imagens, impregna-se de conceitos (emergentes da cultura em que se inserem) por meio dos quais o redator tenta estimular a imaginação do leitor. A mente interpretadora se tornará tanto mais capaz de produzir imagens - sob o estímulo do texto - quanto mais icônico ou indiciais forem os signos com que é tecido o texto, pois a semiose é um processo de produção de significados. O sentido 
é a resultante da interpretação de um significado emergente da estrutura textual e contextual de que participa, e o leitor (ou intérprete) procura desvelar um sentido que estabeleça a comunicação entre ele (leitor, coautor) e o autor primeiro do texto. (SIMÕES, 2009, p. 59-60)

A TIV concebe a compreensão textual como "uma negociação entre imagens mentais construídas por um enunciador e reconstruídas por um coenunciador" (SIMÕES, 2009, p. 75). Por meio do código linguístico, essa negociação reflete mundos particulares dos interlocutores envolvidos no processo de interação. Desencadeia-se daí a plasticidade textual, que é referência de iconicidade, que pode conduzir o intérprete à compreensão da mensagem inscrita na trama textual tanto no nível abstrato como no nível concreto. Este se refere à iconicidade diagramática que é construída no eixo paradigmático e sintagmático, enquanto aquele concerne à modalidade imagética e metafórica que é abstrato pelo fato de a percepção do plano icônico-indicial da imagem e do icônico-simbólico da metáfora consistir em operações subjetivas.

Diante desses apontamentos, percebe-se que a Teoria da Iconicidade Verbal se edifica a partir das seguintes proposições: 
1. O signo verbal é uma imagem (sonora ou visual);

2. A seleção e a combinação produzem a iconicidade textual no nível diagramático;

3. O projeto comunicativo funda-se na verossimilhança e visa a eficácia textual;

4. O texto deve também ser analisado em seus atributos plásticos;

5. A eficiência do projeto de dizer é a comunicação de uma mensagem verdadeira ou falaciosa;

6. Há intima relação entre a iconicidade da imagem textual e a cognição e

7. As imagens textuais ativam imagens mentais (espaços cognitivos) que deflagram raciocínios. (SIMÕES, 2009, p. 74-75)

Avançando a discussão, Simões (2009) aponta que, além do plano da estrutura gramatical, a Teoria da Iconicidade Verbal permite analisar a trama textual a partir da seleção vocabular praticada pelo autor que iconicamente faz emergir as matrizes interpretativas do texto - neste particular, a TIV se encontra com a perspectiva de Halliday ([1985] 2004). É possível observar que a autora reconhece a existência de uma estreita relação entre a seleção vocabular, a produção de iconicidade e a arquitetural textual:

Reconhecendo que a leitura de textos procede de uma negociação entre imagens mentais construídas por um enunciador 
e reconstruídas por um coenunciador (leitor ou intérprete), que tais imagens são traduzidas em signos verbais e não-verbais combinados na folha de papel (no caso do texto escrito) e que tanto a enunciação quanto a coenunciação refletem mundos particulares mediados (no caso) pelo código verbal, entendemos que a plasticidade textual é referência de iconicidade e pode funcionar como a base para a condução do intérprete à mensagem básica inscrita no texto. (SIMÕES; DUTRA, 2004b, p. 38)

Esses apontamentos justificam a eleição, nesta pesquisa, da Teoria da Iconicidade Verbal, como construto teórico. Ela permitirá averiguar no romance-córpus como as escolhas incongruentes realizadas por José J. Veiga arquitetam um texto que iconicamente é marcado por fenômenos insólitos.

Simões (2009) ainda apresenta tipos ou níveis de iconicidade que auxiliam na aplicação da TIV: (1) diagramática - relativa ao plano visual ou sonoro e à sua organização em sintagmas; (2) lexical - refere-se à eleição, recorrência e coocorrência lexical que é responsável pela ativação de imagens mentais; (3) isotópica - demarca os blocos semânticos construídos pelas escolhas lexicais que indicam o itinerário de leitura para o texto; (4) alta ou baixa iconicidade - ocorre em função das escolhas 
lexicais feitas que podem levar o texto a (não) cumprir seu propósito comunicativo; (5) eleição de signos orientadores e desorientadores - configura a presença de signos que (não) pode conduzir o intérprete pela superfície textual.

\subsection{ICONICIDADE DIAGRAMÁTICA}

A iconicidade diagramática, segundo Simões, é projetada no texto a partir do plano visual (na escrita) e sonoro (na fala) e da organização dos sintagmas. Ela produz imagens acopladas ao projeto de raciocínio traçado pelo autor do texto:

Pode ser dedutiva ou indutiva. Esta vai reunindo um a um os signos de que se constitui o texto de modo a compor o seu significado global; enquanto aquela parte do todo do texto e tenta decompô-lo em partes menores que possam referendar a ideia global que lhe fora atribuída. (SIMÕES, 2009, p. 83)

Essas estratégias da cognição, apoiadas nas marcas formais presentes na arquitetura textual, facilitam a produção de sentido de um texto oral ou escrito. Em um texto oral, os elementos prosódicos (cf. MASSINI-CAGLIARI; CAGLIARI, 2003) geram "a iconicidade diagramática e conduzem o interlocutor na produção da semiose, que é a dedução ou indução dos significados ativados pelo enunciador, da qual 
nasce o sentido do texto" (SIMÕES, 2009, p. 83). Já no texto escrito a iconicidade diagramática desponta a partir do plano "(1) gráfico ou do design textual (que consiste na distribuição dos signos na folha de papel) e (2) que opera nos eixos de seleção e combinação dos signos, conforme propusera Saussure no Curso de Linguística Geral (19101913)" (SIMÕES, 2009, p. 83).

Nessa perspectiva, a iconicidade diagramática verbal se estrutura primordialmente a partir das escolhas lexicais que o autor realiza para produzir seu texto. A seleção adequada dos itens léxicos (palavras e expressões) pode garantir a eficiência da iconicidade material projetada no texto:

A iconicidade material no texto escrito se mostra, por exemplo, na distribuição do conteúdo textual em parágrafos; a apresentação do texto por um título e das porções ou seções internas do texto por subtítulos. O uso de maiúsculas, de capitulares etc. os recursos gráficos como itálico, negrito, os travessões, parênteses, colchetes, aspas etc. constituem material constitutivo da plasticidade material, objetiva, do texto. (SIMÕES, 2009, p. 85)

Em síntese, apoiado nas palavras de Simões (2009), a diagramação textual fundada na estruturação do texto em parágrafos e na sua organização na página indica o itinerário de leitura. Além disso, a seleção e a combinação dos itens 
léxicos no eixo paradigmático e sintagmático se relacionam com a iconicidade lexical.

\subsection{ICONICIDADE LEXICAL}

A iconicidade lexical refere-se ao potencial sígnico dos itens lexicais arquitetado pelas escolhas lexicais realizadas pelo enunciador para a produção de seu texto. Assim, podese dizer que o projeto comunicativo edificado no texto pela seleção lexical "produz uma energia mental capaz de ativar signos que possam representar (ícones) ideias ou conduzir (índices) o interlocutor à mensagem básica da comunicação" (SIMÕES, 2009, p. 86). Destarte, a habilidade do enunciador em realizar escolhas lexicais adequadas garantirá a produção de um texto altamente icônico:

Essa habilidade demanda domínio razoável da língua-objeto, assim como largo repertório. O domínio da língua é o esqueleto sistêmico para estruturação textual; e o repertório amplo é condição para disponibilização de itens léxicos suficientes à expressão das ideias de forma icônica. A representação do pensamento será tão mais icônica quanto mais proficiente for o enunciador; da mesma forma que a comunicação será tão mais efetiva quanto mais proficientes forem os interlocutores. (SIMÕES, 2009, p. 86-87)

Amparado em Simões (2004c), fica claro que a organização das escolhas lexicais no eixo paradigmático 
e sintagmático faz despontar pistas icônicas e indiciais, "em cuja combinação formar-se-ão as imagens semânticopragmáticas que subsidiarão a leitura e a compreensão" (SIMÕES, 2009, p. 87) textual.

Perseguindo essa assertiva, a análise do plano lexical, edificado por tessituras morfossintáticas, conduz à compreensão de que a imagem mental construída pela palavra/signo - mediante o processo de representação faz despontar a mensagem inscrita na arquitetura textual (HAENSCH et al., 1982). Cabe destacar também que a ironia, o insólito, o trágico e o cômico se manifestam no texto por meio de seu "potencial icônico e indicial e de sua organização sintática" (SIMÕES, 2009, p. 88).

\subsection{ICONICIDADE ISOTÓPICA}

A iconicidade isotópica se desponta por meio da iconicidade diagramática e da iconicidade lexical. Por meio de signos-chave, ela demarca os recortes temáticos que indicam a construção de sentido do texto. Nesta pesquisa, a iconicidade isotópica torna-se necessária para a análise, uma vez que ela permitirá verificar como as escolhas lexicais e as combinações incongruentes garantem a manifestação de modo essencial do insólito no romance Sombras de Reis Barbudos, de José J. Veiga. 
Avançando a discussão, com apoio nas palavras de Simões (2009, p. 89) que reiteram a importância da iconicidade isotópica para a análise textual:

No plano da análise de textos em geral, a iconicidade isotópica se faz no rastreamento de palavras e expressões que possam sustentar esse ou aquele tema. A garantia dos recortes isotópicos propostos para esse ou aquele texto se assenta exatamente na possibilidade de identificação de itens léxicos (palavras ou expressões) que constituam campos semânticos que ratifiquem a opção temática proposta.

Eis as questões que despontam ao indicar as isotopias textuais como uma construção sustentada pela iconicidade lexical:

(a) O levantamento lexical pode demarcar o recorte temático do texto-córpus?

(b) O mapeamento dos itens lexicais sugere iconicamente o recorte das isotopias presentes em um texto em que se manifesta o insólito de modo essencial?

Naturalmente, pode-se dizer que a seleção lexical permite ao intérprete (leitor) identificar os recortes temáticos do texto em análise. Se os campos semânticos se mostram na superfície da tessitura textual, trabalha-se com um texto com alta iconicidade, enquanto a arquitetura textual, que se 
mostra a partir da opacidade, depara-se com um texto com baixa iconicidade.

\subsection{ALTA OU BAIXA ICONICIDADE}

Como uma das pretensões desta pesquisa é a de analisar as imagens construídas em um romance em que o insólito se manifesta de modo essencial, não há como negar a importância do potencial icônico dos signos que indicam o itinerário de leitura do texto. Segundo Simões (2009), a iconicidade se revela na arquitetura textual a partir das escolhas lexicais que o enunciador faz para cumprir o projeto comunicativo. Ela afirma ainda que a seleção dos itens léxicos feita pelo enunciador estabeleceria a alta ou a baixa iconicidade.

Temos como alta iconicidade a realização de um projeto comunicativo, porém, sem compromisso com a verdade. Já a baixa iconicidade é resultado do mau uso do código linguístico. Para concretizar a alta iconicidade, impõe-se domínio verbal tal que permita a eleição de signos adequados ao cumprimento do projeto comunicativo. (SIMÕES, 2009, p. 96)

A autora defende que o bom ou mau uso da língua e a amplitude do repertório utilizado pelo enunciador na construção do projeto comunicativo determinarão o grau da iconicidade; ou seja, "se o texto consegue atingir 
seus objetivos comunicativos, classificamo-lo como de alta iconicidade; caso contrário será um texto de baixa iconicidade" (SIMÕES, 2009, p. 95).

É importante esclarecer que a linguagem de alguns textos é marcada pela objetividade e a de outros pela subjetividade, entretanto, não é isso que irá determinar a alta e baixa iconicidade, mas a eleição de signos adequados ao projeto comunicativo. Os textos literários, por exemplo, são marcados pela subjetividade. Embora a princípio possam parecer opacos, com baixa iconicidade para um leitor desavisado, estes oferecem pistas eficientes e suficientes que indicam o itinerário de leitura a partir de um jogo inteligente com a alta iconicidade (SIMÕES; ASSIS, 2012).

Nessa perspectiva, os signos icônicos no romance Sombras de Reis Barbudos tornam-se polissêmicos e pluridimensionais porque José J. Veiga os construiu a partir de um jogo inteligente com a alta iconicidade, que é depreendida sem esforço por parte do leitor (intérprete).

\subsection{ELEIÇÃO DE SIGNOS ORIENTADORES OU DESORIENTADORES}

Os signos presentes na superfície textual podem ser orientadores e desorientadores do intérprete pelas trilhas do texto em busca do sentido; ou seja, o enunciador no momento da produção textual (seja oral, seja escrita) elege 
"signos que conduzem ou não o interlocutor pela superfície textual" (SIMÕES, 2009, p. 96) na descoberta do projeto comunicativo subjacente ao texto. De acordo com Simões,

na semiótica linguística de extração peirceana, é possível identificar a faculdade que os signos têm de funcionarem como avesso de si mesmos. Os ícones que atuam no eixo da semelhança e os índices, na contiguidade, aparentemente funcionariam sempre como condutores da leitura. Todavia, dependendo das intenções comunicativas do enunciador, tais signos podem convolar em símbolos e assim atuarem como complicadores da leitura, funcionando então como signos desorientadores. (2004b, p. 137)

Amparado nas palavras da autora, nota-se que o intérprete, para chegar à compreensão do sentido do texto, precisa ter domínio vocabular da língua e saber selecionar os significados adequados ao projeto comunicativo inscrito na arquitetura textual. Nessa perspectiva, o sentido do texto é construído na interação enunciador-texto-intérprete $(\mathrm{KOCH}$, 2008), sendo a leitura um momento de interação em que o intérprete (leitor) busca reconstruir o caminho percorrido pelo enunciador por meio das pistas icônicas deixadas por meio da trilha léxica.

Pensando no texto-córpus desta pesquisa, é possível dizer que, em um texto literário em que o insólito se manifesta 
de modo essencial, as astúcias enunciativas demandam ampla competência do intérprete para desvendar o fato polissêmico, pluridimensional.

\section{A INTERPRETAÇÃO DOS SIGNOS INSÓLITOS E SEUS LIMITES}

O insólito, como categoria essencial do fantástico modal, elege a ambiguidade semântica como fenômeno linguístico ao instaurar um enigma que digladia com a ordem natural e normal da realidade epidérmica; ou seja, o texto literário em que se manifesta o insólito de modo essencial é construído pelo "discurso de um mundo dotado de propriedades contraditórias e ambíguas, que não podem ser verificadas fora do texto e da situação comunicativa" (ARÁN, 1999, p. 12).

Nessa concepção, pode-se argumentar que os signos responsáveis pela construção do fenômeno insólito geram imagens mentais ao romperem com a realidade empírica, sendo que seu funcionamento semiótico abre caminho para múltiplas interpretações. Entretanto, os fenômenos insólitos produzem ilimitados signos capazes de construir um mundo possível apenas no universo literário, mas cujo pano de fundo é a realidade empírica.

Destarte, a tessitura de texto emoldurado pelo macrogênero/arquigênero fantástico apresenta simultaneamente propriedades (não) semelhantes às do 
mundo empírico, de modo que a verossimilhança interna cria um mundo possível (ARÁN, 1999). A função do signo insólito, nesse universo, é interrogar o mundo cotidiano de modo que sua atuação linguística na arquitetura textual seja responsável pela construção do projeto comunicativo do texto, sujeito às leis ficcionais que regem o fantástico modal.

No contexto descrito, o insólito se manifesta como um fenômeno semântico, verbal ou linguístico pelo fato de sua linguagem transgredir o plano de enunciação (CASAS, 2010). Assim, é perceptível no discurso em que se manifesta o fantástico uma transgressão não só da nossa percepção de real como também do potencial referencial que atribuímos às palavras. Julga-se, portanto, que "uma mínima modificação, alteração ou mudança a nível verbal, uma ruptura linguística mínima, pode provocar a irrupção do impossível" (CASAS, 2010, p. 11), que abre caminho para a pluralidade interpretativa do fenômeno insólito.

Nota-se ainda que na arquitetura textual dos fenômenos insólitos há uma incompletude significativa, uma vez que

são habituais o emprego de termos ambíguos, vagos, para definir aspectos de um mundo tão impossível como indefinível; o uso de símiles, metáforas e símbolos que nos permitem intuir antes de conhecer; ou a presença de paradoxos e equívocos 
para apresentar acontecimentos que contradizem outros da realidade textual. Em concreto, o fantástico como fenômeno de linguagem se relaciona ao conceito de impertinência, que consiste na justaposição de campos semânticos, se não incompativel, totalmente desvinculado, e tem por objeto configurar uma realidade distinta da convencional por meio de uma conjunção semântica não codificada e, por ela, insólita. (CASAS, 2010, p. 11)

Com base nesses apontamentos, o texto em que o insólito se manifesta de modo essencial, em função dos elementos expressivos eleitos pelo enunciador no momento de sua produção, torna-o aberto a mais de uma possibilidade interpretativa, sem, no entanto, perder de vista o que Eco (2001; 2008) denominou cooperação interpretativa e limites da interpretação.

Para Eco, é notório o papel ativo do intérprete na descoberta do projeto comunicativo do fenômeno insólito. Isso faz despontar também a noção de semiótica ilimitada. Segundo o semioticista,

a noção de uma semiótica ilimitada não leva à conclusão de que a interpretação não tem critérios. Dizer que a interpretação (enquanto característica básica da semiótica) é potencialmente ilimitada não significa que a interpretação não tenha objeto e que corra por conta própria. Dizer que um texto potencialmente não tem fim 
não significa que todo ato de interpretação possa ter um final feliz. [...] Interpretar um texto significa explicar por que essas palavras podem fazer várias coisas (e não outras) através do modo pelo qual são interpretadas. (ECO, 2003, p. 28)

De acordo com Simões, o texto em que se manifesta o insólito de modo essencial trilha "um caminho complexo, por reunir numa mesma superfície signos de tipos variados, cuja carga semiótica é individual (do ponto de vista da escolha do enunciador) e interindividual (considerada a sua pertinência a um sistema histórico-cultural)" (2007, p. 20). Os signos icônicos tornam-se polissêmicos e pluridimensionais, pois o autor consegue construí-los a partir de um jogo inteligente com a alta iconicidade que é depreendida sem esforço por parte do leitor (intérprete).

Em síntese, os limites interpretativos dos fenômenos insólitos se inscrevem na iconicidade dos itens lexicais que são pistas verbais ao promoverem a compreensão e a interpretação do texto literário. Trata-se de uma perspectiva de análise que partilha da interpretação em aberto, característica da obra de arte, e respeita os limites do signo-texto. Desse modo, o léxico é sempre um componente fundamental para a leitura de textos. Assim, o romance-córpus desta pesquisa (assim com qualquer texto 
literário) contém uma estrutura reguladora da leitura, a qual permite desvendar vários recortes isotópicos para o texto, sem, contudo, torná-lo "terra de ninguém", onde tudo é permitido. O signo está disponível à semiose ilimitada (PEIRCE, 1931), porém seus limites vão sendo construídos a partir da atualização do signo nos textos. Estes, por sua vez, são enquadrados em contextos sócio-históricos que determinam as possibilidades de inferir significações na construção das leituras. Em outras palavras, o texto tem um limite isotópico construído por uma estrutura ausente (Eco, 1997), mas que controla de certo modo a interpretação.

\section{A ICONICIDADE LEXICAL EM PASSAGENS INSÓLITAS}

\section{Breve resumo do romance-córpus}

O romance Sombras de Reis Barbudos, de José J. Veiga, pode ser assim resumido: uma poderosa companhia, logo que se instala em uma cidade, altera a vida da comunidade, com a imposição de rigorosas regras de comportamento. A referida companhia mantém enclausurada a comunidade daquela cidade, tornando-a refém de suas rigorosas determinações. Muito cedo, o pânico, o medo, o terror e a desconfiança dominam o lugar. As pessoas vivem assombradas, perdem a liberdade até de pensar. Nesse clima de tensão se desenrolam ações e fenômenos insólitos - cidade é tomada por muros e urubus e as pessoas começam a voar.

Com a ajuda do programa digital Wodrsmith Tools, levantou os substantivos desencadeadores do insólito e 
suas concordâncias, com o objetivo de apreciar o potencial icônico dos fenômenos insólitos que compõem o romance de José J. Veiga.

Optou-se por analisar a iconicidade apenas dos substantivos do romance-córpus, pelo fato de os nódulos desencadeadores do insólito serem palavras lexicais pertencentes a essa classe gramatical. Como são palavras lexicais, os substantivos são palavras cheias; ou seja, são lexias que possuem significados (CARTER, 1998) gerados a partir de uma imagem mental. Além disso, o "substantivo significa literalmente o que está debaixo, na base. [Eles] são fundamentos do texto, pois não se pode construir um texto sem utilizar essa classe" (CASTILHO, 2010, p. 455).

No texto veiguiano, os substantivos são palavras com alta iconicidade que designam os seres e seus atributos, suas qualidades e seus atos próprios como se fossem entidades separadas deles (SAID, 1964). Esses itens lexicais são categorias linguísticas caracterizáveis semanticamente por terem um potencial de referência, isto é, por terem no romance a função designatória ou de nomeação que envolve, do ponto de vista cognitivo, diferentes graus de abstração e complexidade conceptual (MATEUS, 2003; ANTUNES, 2003). Além disso, eles designam "entidades cognitivas e/ou 
culturais que possuem certas propriedades categorizadas no mundo extralinguístico" (NEVES, 2000, p. 68).

Irmanados às palavras de Antunes (2003), pode-se dizer que os substantivos, urdidos na tessitura textual do romance Sombras de Reis Barbudos, são signos que, ao referirem-se às pessoas e às coisas na arquitetura textual, com sua alta iconicidade, desempenham a função referencial na atividade do enunciador. Por isso, os substantivos utilizados por José J. Veiga apresentam um potencial icônico capaz de construir a trilha de leitura de Sombras de reis barbudos.

Depois de levantar os substantivos cujo potencial icônico deflagra processos cognitivos que geram imagens figurativas ou diagramáticas na mente leitora, a partir das quais se constroem a compreensão e a interpretação do textocórpus, planifica-se em um quadro item a item, de modo a apresentar um estudo que leva em conta sua significação dicionarizada mais adequada ao projeto comunicativo do romance e sua função semiótica. As interpretações expostas a seguir baseiam-se no quantitativo e nas pistas textuais encontradas no contexto. Por isso, desenvolvem-se também gráficos com as ocorrências dos itens no texto e algumas passagens à guisa de ilustração do potencial icônico dos substantivos no romance-córpus. 
O projeto comunicativo do romance-córpus ativa signos insólitos que podem representar (ícones) ideias ou conduzir (índices) o intérprete à compreensão de que o insólito é construído no texto por meio de pistas icônicas que retratam um quadro opressivo (muros), a realidade invertida (urubus) e a busca da liberdade cerceada (homens-pássaros). É oportuno acompanhar a iconicidade dos itens lexicais que são os nódulos geradores do insólito.

O levantamento realizado com o Programa WordSmith Tools produziu o seguinte gráfico (Quadro 1) a partir da frequência de cada substantivo-nódulo dos eventos insólitos presentes no romance:

Quadro 1: Gráfico da frequência de vocábulos no texto

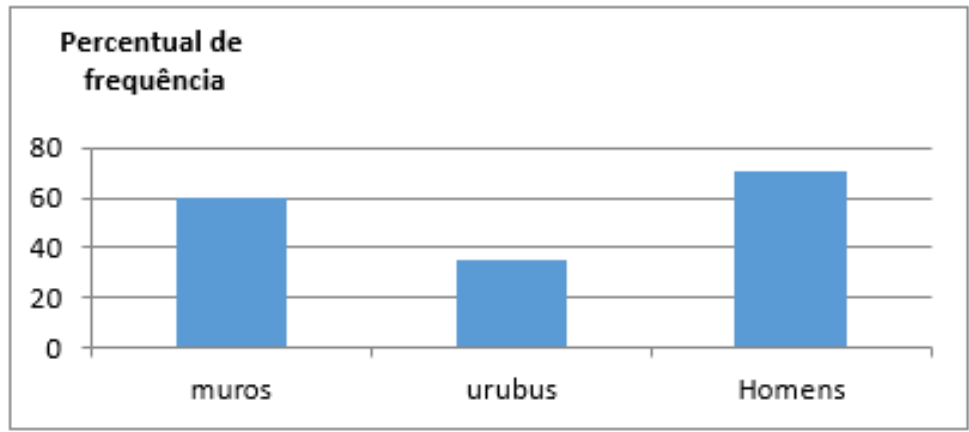

Fonte: Assis, 2017, p. 165

Ao exemplificar os levantamentos dessa natureza, demonstram-se o ajuste entre as escolhas léxicas, o tema e os subtemas que atravessam o texto. No romance em foco, 
o tema se constitui pelo binômio liberdade versus opressão. Agora resta acompanhar o potencial icônico desses substantivos (Quadro 2):

Quadro 2: Iconicidade dos eventos insólitos

\begin{tabular}{|c|c|c|c|c|}
\hline $\begin{array}{c}\text { ITEM } \\
\text { LEXICAL }\end{array}$ & $\begin{array}{l}\text { INFORMAÇÃO } \\
\text { SUBJACENTE }\end{array}$ & $\begin{array}{c}\text { SIGNIFICAÇÃO } \\
\text { DICIONARIZADA }\end{array}$ & $\begin{array}{l}\text { FUNÇÃO } \\
\text { SEMIÓTICA }\end{array}$ & $\begin{array}{l}\text { ISOTOPIAS } \\
\text { POSSIVEIS }\end{array}$ \\
\hline Muros & \multirow{3}{*}{ 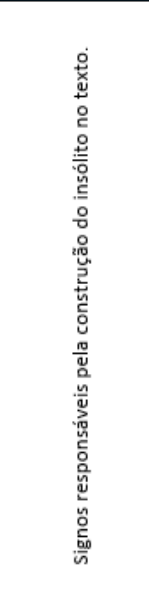 } & $\begin{array}{l}\text { Muros - (1) paredes fortes que } \\
\text { circundam um recinto ou separam } \\
\text { um lugar de outro; (2) símbolo de } \\
\text { separação; (3) separação entre } \\
\text { famílias, entre Deus e a criatura, } \\
\text { entre o soberano e povo; (4) muro } \\
\text { é comunicação cortada, com a sua } \\
\text { dupla incidência psicológica: } \\
\text { segurança, sufocação; defesa, mas } \\
\text { prisão. }\end{array}$ & $\begin{array}{l}\text { Ícone da liberdade } \\
\text { cerceada. } \\
\text { Índice de } \\
\text { opressão }\end{array}$ & $\begin{array}{l}\text { Opressão } \\
\text { Insólito }\end{array}$ \\
\hline Urubus & & $\begin{array}{l}\text { Urubus - (1) Aves catarttídeas } \\
\text { pretas, de cabeças nuas, que se } \\
\text { alimentam de carnes em } \\
\text { decomposição. }\end{array}$ & $\begin{array}{l}\text { Ícone da inversão } \\
\text { da ordem. }\end{array}$ & $\begin{array}{l}\text { Insólito } \\
\text { Negatividade }\end{array}$ \\
\hline $\begin{array}{l}\text { Homens- } \\
\text { pássaros }\end{array}$ & & $\begin{array}{l}\text { Homens - (1) indivíduo } \\
\text { pertencente à espécie animal que } \\
\text { apresenta o maior grau de } \\
\text { complexidade na escola evolutiva. }\end{array}$ & $\begin{array}{l}\text { Ícone do desejo } \\
\text { de sublimação, de } \\
\text { busca de } \\
\text { harmonia interior, } \\
\text { de ultrapassagem } \\
\text { dos conflitos. }\end{array}$ & $\begin{array}{l}\text { Insólito } \\
\text { Liberdade }\end{array}$ \\
\hline
\end{tabular}

Fonte: Assis, 2017, p. 165-166

A iconicidade do léxico mostrada no quadro anterior baseou-se não só no quantitativo lexical levantado automaticamente pelo programa WordSmith Tools, mas, sobretudo, por pistas textuais maiores que permitiram a visualização da cena, dando à narrativa uma qualidade fílmica. Transcrevem-se a seguir algumas passagens, extraídas do romance aleatoriamente, à guisa de ilustração da potencialidade pictórica, imagética, icônica, do textocórpus (Quadro 3): 
Quadro 3: Concordâncias dos nódulos geradores do insólito

\begin{tabular}{|c|c|}
\hline PÁGINA & TRECHOS ESCOLHIDOS \\
\hline 30 & $\begin{array}{l}\text { De repente os } \underline{\text { muros, }} \text { esses } \underline{\text { muros. Da noite para o dia }} \\
\text { os } \underline{\text { muros brotaram assim retos, curvos, quebrados, }} \\
\text { descendo, subindo, dividindo as ruas ao meio conforme o } \\
\text { traçado, separando amigos, tapando vistas, escurecendo, } \\
\text { abafando. }\end{array}$ \\
\hline 49 & $\begin{array}{l}\text { As crianças logo fizeram amizade com eles, quase } \\
\text { todo menino (e menina também) tinha um urubu } \\
\text { para acompanhá-lo como um cachorrinho até na rua, } \\
\text { espontaneamente ou puxado por uma corda presa com } \\
\text { laço frouxo no pescoço apenas para indicar a direção. } \\
\text { [...] Mas como tempo todos se acostumaram a viver em } \\
\text { intimidade com os urubus, e a cidade inteira sofreu por eles } \\
\text { quando a Companhia começou a persegui-los. }\end{array}$ \\
\hline 122 & $\begin{array}{l}\text { o homem passava voando bem na minha frente, } \\
\text { justamente diante da parte aberta da torre! Foi rápido, } \\
\text { mas deu para ver. la deitadinho como nadando, só que } \\
\text { não dava braçadas, apenas mexia discretamente com } \\
\text { os braços, e me pareceu que tinha um cigano aceso na } \\
\text { boca, se não era cigarro era um canudinho outro que } \\
\text { também soltava fumaça. }\end{array}$ \\
\hline 134 & Lá no alto os três homens-pássaros continuavam suas \\
\hline
\end{tabular}

Fonte: Assis, 2017, 167

A análise dos substantivos muros, urubus e homenspássaros permite ao intérprete descobrir no universo aberto do texto do escritor goiano que o aparecimento inesperado de muros na cidade revela sinais claros da opressão. Esses indícios impõem limites e cerceiam a liberdade individual; por sua vez, a intimidade do homem com os urubus representa um lenitivo para a opressão e o voo do homem como meio para buscar a liberdade cerceada. 
Rastreando a trilha léxica dos três eventos insólitos presentes no texto-córpus, nota-se que, misteriosamente, eles são desencadeados pela ação da Companhia Melhoramentos de Taitara. Além disso, eles constroem o binômio liberdade versus opressão, o tema abordado no texto. O primeiro evento instaura a opressão; o segundo apresenta um meio para que as pessoas tentem conviver com a ação repressiva; e o último expressa a busca pela liberdade.

Assim, o potencial icônico dos três itens lexicais demonstra que o aspecto inusual, incongruente, impossível, inusitado, incorrigível, inaudito e inverossímil dos acontecimentos narrados no romance Sombras de Reis Barbudos não pode ser submetido às leis da racionalidade.

É interessante perceber como José J. Veiga consegue garantir a continuidade de sentido em seu romance, construindo fenômenos que manifestam o extraordinário, o incoerente e o incongruente. Os signos expressos nesta passagem apontam que o tempo da trama textual é inesperado. Muros surgem e distribuem-se por todos os lados, em todas as direções, dividindo, cobrindo, isolando. É tudo tão rápido que os muros parecem brotar do chão ou ter sido plantados. 
A potencialidade imagética dos signos que compõem a arquitetura textual desse fenômeno insólito permite perceber a chave do insólito do trecho: "Da noite para o dia eles brotaram assim retos, curvos, quebrados, descendo, subindo". A análise da iconicidade lexical propicia visualizar que o aparecimento repentino desse fenômeno insólito, que transgride a ordem regular do espaço taitariano, leva os homens a tentarem adaptar-se às imposições que lhes são feitas paulatinamente, o que é representado por aqueles muros que, de forma indireta, remetem ao poder do estatal sobre o indivíduo.

O entendimento, portanto, da iconicidade acionada pelo léxico dessa passagem, resultará na instalação aparentemente inquestionável do insólito no romance, que desencadeia situações desesperadoras e provoca a perda da liberdade de viver.

O quadro opressivo descrito na trilha léxica prende os taitarenses em suas próprias casas, porque ir às ruas se tornou perigoso. Nesse clima de opressão, outros acontecimentos incongruentes desencadeiam-se na trama textual: "Em qualquer lugar só se via muro, a menos que se olhasse para cima" (VEIGA, 2001, p. 37). "Principalmente urubus. Não sei se era ilusão, se tinha sido assim sempre; mas depois que adquirimos o hábito de descansar a vista dos muros olhando 
para cima ficou parecendo que o número de urubus sobre a cidade estava aumentando dia a dia" (VEIGA, 2001, p. 38).

A iconicidade desse trecho permite visualizar que o insólito se constrói mediante o uso da palavra urubus. Na tradição judaico-cristã, o olhar para cima significa a busca da divindade. Para as personagens de Veiga, olhar para cima e contentar-se com apreciar urubus - "bichos nojentos" são atitudes que passam a fazer parte da rotina letárgica dos moradores da cidade.

O urubu é uma ave de rapina que se alimenta principalmente da carne de animais mortos (carniça), razão por que é também considerado por alguns povos como ave de mau agouro (CASCUDO,1993). A despeito disso, as imagens icônicas projetadas na narrativa em análise trazem os urubus como uma saída para os prisioneiros da companhia. Olhar e contar urubus passam a ser uma diversão. O convívio com os urubus metaforiza a relação entre os moradores e os homens da Companhia, resultando em uma realidade revertida:

As crianças logo fizeram amizade com eles, quase todo menino (e menina também) tinha um urubu para acompanhá-lo como um cachorrinho até na rua, espontaneamente ou puxado por uma corda presa com laço frouxo no pescoço apenas para indicar a direção. (VEIGA, 2001, p. 49) 
O que se vê é uma total inversão de valores. A situação é tão caótica que "estes bichos antes tão malquistos" (VEIGA, 2001, p. 45) parecem transformar-se em lenitivo de uma vida sem perspectiva: "[...] com o tempo todos se acostumaram a viver em intimidade com os urubus, e a cidade inteira sofreu por eles quando a CIA começou a persegui-los" (p. 49).

As proibições ditadas pela Companhia traziam cada dia mais sofrimento à população. Esta, no entanto, consegue se adaptar e cria subterfúgios para não sucumbir:

Todo mundo vem dizendo há muito tempo que a vida está insuportável, e que se continuar assim... Pois continua, e cada dia piora, e estamos aí aguentando. Quando parece que não vamos aguentar mais e cair no desespero, alguém inventa um passatempo para nos distrair. (VEIGA, 2001, p. 116)

O último passatempo apresentado é o voo dos homens. O surgimento desse novo evento insólito gera temor nos habitantes, pois poderia ser "uma nova manobra da Companhia" (VEIGA, 2001, p. 123). Mas, quando percebem que até a companhia está atemorizada, têm um novo alento, porque, "se a novidade era ruim para a Companhia, tinha que ser boa para nós" (p. 132). Então, o espetáculo dos homenspássaros passa a ser apreciado verdadeiramente. Esse passatempo pode ser interpretado, em primeira instância, 
como uma atitude de profundo desconforto, que evidencia o desdobramento dos signos de forma extraordinária. O divertimento rompe com atitudes habituais, comuns, costumeiras, usuais e frequentes. Enfim, surpreende as expectativas cotidianas e resulta num choque afetivo, de modo a desorganizar e desnudar a representação do real em Taitara. Depois, o fenômeno insólito deixa de ser o outro lado, o desconhecido em Taitara, e incorpora-se ao real. As imagens criadas pelo voo dos homens libertam o espírito da realidade imediata imposta pela Companhia Melhoramentos. Ao acontecer essa irrupção de imagens, explode daquele cotidiano a transgressão da realidade de Taitara, de modo a ir além do concebível e do dizível, tal como determina o pensamento imposto pela Companhia.

Assim, os fenômenos insólitos no romance estruturam, tematicamente, a constância do binômio opressão versus liberdade. A instalação aparentemente inquestionável do insólito desencadeia o sentimento de pânico na cidade de Taitara, gerando situações desesperadoras que provocam a perda da liberdade de viver.

Se, no princípio da trama, o aparecimento dos muros insólitos (retos e curvos) provoca a perda da liberdade, no fim, os insólitos homens-pássaros exprimem um desejo de 
sublimação ou de liberdade, de busca de harmonia interior, de superação dos conflitos. Em uma comunidade onde estavam cerceadas todas as formas de liberdade individual, a última alternativa para seus membros seria a de voar.

Em síntese, o insólito construído pela incongruência lexical presente na obra do escritor goiano caracteriza, em primeira linha, uma completa atitude de desconforto. Ele rompe com as atitudes habituais, comuns, costumeiras, usuais e frequentes, surpreendendo, enfim, as expectativas cotidianas e criando um choque afetivo, de modo a desorganizar e a desnudar a representação do real em Taitara.

\section{CONSIDERAÇÕES FINAIS}

O objetivo deste estudo foi demonstrar que os fenômenos insólitos se revelam na narrativa literária contemporânea a partir da camada léxica que arquiteta a trama textual. Essa proposta sugere que a ruptura na utilização da linguagem que, por sua vez, refere-se à incompatibilidade das escolhas lexicais realizadas pelo enunciador em relação às estruturas lexicossintáticas da língua - instaura o incongruente e o incoerente na tessitura textual. Para nós, a transgressão representa no texto a presença de coocorrência de estruturas lexicossintáticas (slots) que rompem com o código linguístico e iconicamente garantem a construção da insolitude no texto 
literário. As estruturas lexicogramaticais, presentes no textocórpus, refletem bem o aspecto unusual do fenômeno insólito: "os muros brotaram", "o homem passava voando", entre outras.

A análise dos dados demonstrou que a incongruência e a iconicidade lexical são delineadas a partir do léxico que representa ideias ou conduz o intérprete à percepção de que o insólito é construído no texto por meio de pistas icônicas. Diante dessas evidências, torna-se notório também que os substantivos, por serem palavras com alta iconicidade, participam da construção/representação de fenômenos insólitos e criam, por meio da trilha léxica, o itinerário de leitura para o texto-córpus. Com base em tais apontamentos, os substantivos, como categorias linguísticas caracterizáveis semanticamente, têm a função designatória ou de nomeação na arquitetura textual dos fenômenos insólitos de José J. Veiga.

\section{REFERÊNCIAS}

ANTUNES, Irandé. Aula de Português: encontro e interação. São Paulo: Parábola, 2003.

ARÁN, Pampa O. El fantástico Literário: aportes teóricos. Madrid: Tauro Ediciones, 1999.

ASSIS, Eleone Ferraz de. Iconicidade lexical: o Insólito em Sombras de Reis Barbudos. Rio de Janeiro: Dialogarts, 2017.

CARTER, Ronald. Vocabulary: Applied Linguistic Perspectives. London, UK: Routledge, 1998. 
CASAS, Ana. Transgresión linguística y microrrelato fantástico. Insula: Revista de Letras e Ciéncias Humanas, Espanha, v. 765, 2010.

CASTILHO, Ataliba T. de. Nova gramática do Português Brasileiro. São Paulo: Contexto, 2010.

ECO, Umberto. A estrutura ausente. São Paulo: Perspectiva, 1997.

ECO, Umberto. Interpretação e superinterpretação. São Paulo: Martins Fontes, 2001.

ECO, Umberto. Obra aberta: forma e indeterminação nas poéticas contemporâneas. São Paulo: Perspectiva, 2003.

ECO, Umberto. Os limites da interpretação. São Paulo: Perspectiva, 2008. HAENSCH, Günther et al. La lexicografía. De lingüística teórica a la lexicografía práctica. Madrid: Gredos, 1982.

HALLIDAY, Michael Alexander Kirkwood. An Introduction to Functional Grammar. London: Edward Arnold. [1985] 2004.

$\mathrm{KOCH}$, Ingedore. As tramas do texto. Rio de Janeiro: Nova Fronteira, 2008.

MASSINI-CAGLIARI, Gladis; CAGLIARI, Luiz Carlos. Fonética. In: MUSSALIM, Fernanda; BENTES, Anna Christina (Orgs.). Introdução à linguística: domínios e fronteiras. São Paulo: Cortez, 2003.

MATEUS, Maria Helena Mira et al. Gramática da Língua Portuguesa. Lisboa: Caminho, 2003.

NEVES, Maria Helena de Moura. Gramática de usos do Português. São Paulo: Ed. Unesp, 2000.

PEIRCE, Charles Sanders. Collected Papers of Charles Sanders Peirce. Harvard University Press, Cambridge, MA. 1931

SAID, Ali. Gramática secundária da Língua Portuguesa. São Paulo: Melhoramentos, 1964.

SANTAELLA, Lúcia. A teoria geral dos signos: como as linguagens significam as coisas. São Paulo: Cengage Learning, 2000.

SIMÕES, Darcilia; DUTRA, Vânia Lúcia R. A iconicidade, a leitura e o projeto do texto. Linguagem e ensino, Pelotas: UCPel, v. 7, n. 2, jul./ 
dez., 2004a. Disponível em: http://www.rle.ucpel.tche.br/index.php/rle/ article/download/207/174. Acesso em 20 jul. 2008.

SIMÕES, Darcilia. Estudos semióticos. v. 1: Papéis avulsos. Edição digital. Rio de Janeiro: Dialogarts, 2004b. Disponível em: http://www.dialogarts. uerj.br/admin/arquivos_tfc_lingua/estudossemioticos.pdf. Acesso em 20 jul. 2012.

SIMÕES, Darcilia. Semiótica, leitura e produção de textos: alternativas metodológicas Caderno Seminal, Rio de Janeiro: Dialogarts, v. 1, n. 2, 2004c. Disponível em: https://www.dialogarts.uerj.br/admin/arquivos_ seminal/seminal02.pdf\#page=125. Acesso em 20 jul. 2008.

SIMÕES, Darcilia. Iconicidade e verossimilhança: semiótica aplicada ao texto verbal. Edição online. Rio de Janeiro: Dialogarts, 2007. Disponível em: http://www.dialogarts.uerj.br/arquivos/iconicidade_e_verossimilhanca. pdf. Acesso em 20 jul. 2008.

SIMÕES, Darcilia. Iconicidade Verbal: Teoria e Prática. Edição online. Rio de Janeiro: Dialogarts, 2009. Disponível em: http://www.dialogarts.uerj. br/arquivos/iconicidadeverbal.pdf. Acesso em 20 jul. 2011.

SIMÕES, Darcilia; ASSIS, Eleone Ferraz de. Para o enriquecimento do repertório discente. Anais do SIELP, Uberlândia: EDUFU, v. 2. n. 1, 2012. Disponível em: http://www.ileel2.ufu.br/anaisdosielp/pt/arquivos/ sielp2012/997.pdf. Acesso em 2 mar. 2014.

VEIGA, José J. Sombras de Reis Barbudos. Rio de Janeiro: Bertrand Brasil, [1972] 2001.

Eleone Ferraz de Assis é doutor em Língua Portuguesa pela Universidade do Estado do Rio de Janeiro, tendo a tese orientada pela profa. dra. Darcilia Simões, e pós-doutor em Estudos Linguísticos pela Universidade Federal de Goiás. Professor da Universidade Estadual de Goiás onde atua no Programa de Pós-Graduação em Língua, Literatura e Interculturalidade. 